\title{
R-phase and Electronic Structures of TiNi and $\mathrm{TiNi}_{8 / 9} \mathrm{Fe}_{1 / 9}$
}

\author{
Shoji Ishida ${ }^{1}$ and Setsuro Asano ${ }^{2}$ \\ ${ }^{1}$ Department of Physics, Faculty of Science, Kagoshima University, Kagoshima 890-0065, Japan \\ ${ }^{2}$ The Graduate School of College of Arts and Sciences, University of Tokyo, Tokyo 153-0041, Japan
}

Titanium nickel (TiNi) and the pseudo binary containing a small amount of iron has the R phase as an intermediate phase. To examine theoretically the stability of the R phase, the electronic structures of TiNi and $\mathrm{TiNi}_{8 / 9} \mathrm{Fe}_{1 / 9}$ were calculated for four structures of $\mathrm{B} 2$, P3, $\mathrm{P} \overline{3} 1 \mathrm{~m}$ and $\mathrm{P} 31 \mathrm{~m}$. The total energies predict that the P3 structure is most stable among the four structures and in the P3 structure the added iron atoms prefer the $1 \mathrm{c}$ site. It is also revealed that the approach between a nickel (or iron) atom at the $1 \mathrm{c}$ site and a titanium atom at the $1 \mathrm{c}$ site in the P3 structure plays an important role in stabilizing the P3 structure. These features are clearly reflected on the band energies and the local density-of-states of the constituent atoms.

(Received November 20, 2001; Accepted February 15, 2002)

Keywords: R phase, shape memory, titanium nickel (TiNi), electronic structure, P3 structure

\section{Introduction}

The alloy titanium nickel (TiNi) exhibits the shape memory effect which is associated the structural transformation between a $\mathrm{B} 2(\mathrm{CsCl})$ structure and a monoclinic B19' structure. ${ }^{1)}$ However, in pseudo binary alloys containing a third element such as $\mathrm{Fe}$ or $\mathrm{Cu}$ atoms, the intermediate phase of $\mathrm{R}$ phase and/or orthorhombic B19 phase were observed. Although much research on the $\mathrm{R}$ phase has been performed, the questions about the crystal structure of the R-phase remain unanswered.

In this paper, the $\mathrm{R}$ phase is focused. There are two kinds of experimental results about the crystal structure of the $\mathrm{R}$ phase. That is, two types of structures reported are a structure with the trigonal space group $\mathrm{P} \overline{3} \mathrm{~lm}$ symmetry ${ }^{2,3)}$ and a structure with the trigonal space group P3 symmetry. ${ }^{4,5)}$ On the basis of these experimental results, the electronic structures of $\mathrm{TiNi}$ were calculated for the $\mathrm{CsCl}, \mathrm{P} \overline{3} 1 \mathrm{~m}$ and $\mathrm{P} 3$ structures. It was theoretically predicted ${ }^{7)}$ that the $\mathrm{P} 3$ structure is most stable among these structures and that the $\mathrm{Ti}(\mathrm{Ti}(1 \mathrm{c}))$ and $\mathrm{Ni}(\mathrm{Ni}(1 \mathrm{c})$ ) atoms at the $1 \mathrm{c}$ sites in the $\mathrm{P} 3$ structure play an important role in the stabilization of the $\mathrm{P} 3$ structure.

In this paper, it is confirmed that the approach between $\mathrm{Ti}(1 \mathrm{c})$ and $\mathrm{Ni}(1 \mathrm{c})$ atoms contributes largely the stability of the P3 structure, considering an artificial structure with the $\mathrm{P} 31 \mathrm{~m}$ symmetry where the approach between $\mathrm{Ti}(1 \mathrm{c})$ and $\mathrm{Ni}(1 \mathrm{c})$ atoms is suppressed in the P3 structure. Furthermore, as an example of the pseudo binary containing $\mathrm{Fe}$ atoms, $\mathrm{TiNi}_{8 / 9} \mathrm{Fe}_{1 / 9}$ is treated and the stability of the P3 structure is examined on the electronic structures.

\section{Crystal Structure and Method of Calculation}

The parent phase of TiNi is the $\mathrm{CsCl}$ structure. The $\mathrm{P} \overline{3} 1 \mathrm{~m}$ and P3 structures are treated as the P3 structure with 143th group symmetry so as to calculate under the same condition as possible, as mentioned in the previous paper. ${ }^{6}$ That is, all of the crystal structures are assumed to be the P3 structure with a different arrangement along the c-axis in Fig. 1, where the $\mathrm{P} \overline{3} 1 \mathrm{~m}$ and $\mathrm{P} 3$ structures are named as 'Tri1' and 'Tri2', respectively, in this paper. In the $\mathrm{P} 3$ structure, titanium (Ti) and nickel (Ni) are situated at five atomic sites: 1a, 1b, 1c and two kinds of $3 \mathrm{~d}$. Hence, there are five kinds of $\mathrm{Ti}$ and $\mathrm{Ni}$ in the unit cell. Here, these atoms are distinguished such as Ti(1a) and $\mathrm{Ni}(3 \mathrm{~d})$. In the $\mathrm{CsCl}$ structure, the c-planes containing $\mathrm{Ti}$ or $\mathrm{Ni}$ are equally separated but the distances between the cplanes are not equal in the Tri1 and Tri2 structures. In the Tri2 structure, the $\mathrm{Ti}(1 \mathrm{~b})$ and $\mathrm{Ti}(1 \mathrm{c})$ atoms shift from the $\mathrm{Ti}(1 \mathrm{a})$ plane and the $\mathrm{Ni}(1 \mathrm{~b})$ and $\mathrm{Ni}(\mathrm{cc})$ atoms from the $\mathrm{Ni}(1 \mathrm{a})$ plane.

Moreover, we consider an artificial structure with the P31m symmetry where the $\mathrm{Ti}(1 \mathrm{c})$ and $\mathrm{Ni}(1 \mathrm{c})$ atoms in the $\mathrm{P} 3$ (Tri2) structure remain the $\mathrm{Ti}(1 \mathrm{a})$ and $\mathrm{Ni}(1 \mathrm{a})$ planes, respectively. The structure is named as 'Tri3' structure. When we compare the total energies and the electronic structures between the Tri2 and Tri3 structures, the effect of the approach between the $\mathrm{Ti}(1 \mathrm{c})$ and $\mathrm{Ni}(1 \mathrm{c})$ atoms are clarified. The used atomic sites are those given by Hara et al. $\left.{ }^{4}\right)$ which are listed in Table 1.

Band calculations were carried out self consistently by the linear muffin tin orbital (LMTO) and atomic sphere orbital approximation (ASA) method. ${ }^{7)}$ The exchange correlation potential was treated within the framework of the local-spindensity (LSD) approximation. ${ }^{8)}$ The self-consistency was achieved at 112 mesh points in the irreducible Brillouin zone

Table 1 Atomic coordinates for Tri1 and Tri2 structures.

\begin{tabular}{cccccccc}
\hline & \multicolumn{3}{c}{ Tri1 } & & & \multicolumn{3}{c}{ Tri2 } \\
\cline { 2 - 4 } \cline { 6 - 7 } Atom & $x$ & $y$ & $z$ & & $x$ & $y$ & $z$ \\
\hline $\operatorname{Tin}(1 \mathrm{a})$ & 0 & 0 & 0 & & 0 & 0 & 0 \\
$\operatorname{Tin}(1 \mathrm{~b})$ & $1 / 3$ & $2 / 3$ & 0 & & $1 / 3$ & $2 / 3$ & 0.083 \\
$\operatorname{Ti}(1 \mathrm{c})$ & $2 / 3$ & $1 / 3$ & 0 & & $2 / 3$ & $1 / 3$ & 0.009 \\
$\mathrm{Ti}(3 \mathrm{~d})$ & 0 & $2 / 3$ & 0.32 & & 0.335 & -0.004 & 0.361 \\
$\mathrm{Ti}(3 \mathrm{~d})$ & $1 / 3$ & 0 & 0.68 & & 0.677 & 0.01 & 0.684 \\
$\mathrm{Ni}(1 \mathrm{a})$ & 0 & 0 & $1 / 2$ & & 0 & 0 & 0.457 \\
$\mathrm{Ni}(1 \mathrm{~b})$ & $1 / 3$ & $2 / 3$ & $1 / 2$ & & $1 / 3$ & $2 / 3$ & 0.541 \\
$\mathrm{Ni}(1 \mathrm{c})$ & $2 / 3$ & $1 / 3$ & $1 / 2$ & & $2 / 3$ & $1 / 3$ & 0.396 \\
$\mathrm{Ni}(3 \mathrm{~d})$ & $1 / 3$ & 0 & 0.2 & & 0.318 & -0.022 & 0.854 \\
$\mathrm{Ni}(3 \mathrm{~d})$ & 0 & $2 / 3$ & 0.8 & & 0.688 & 0.021 & 0.16 \\
\hline
\end{tabular}



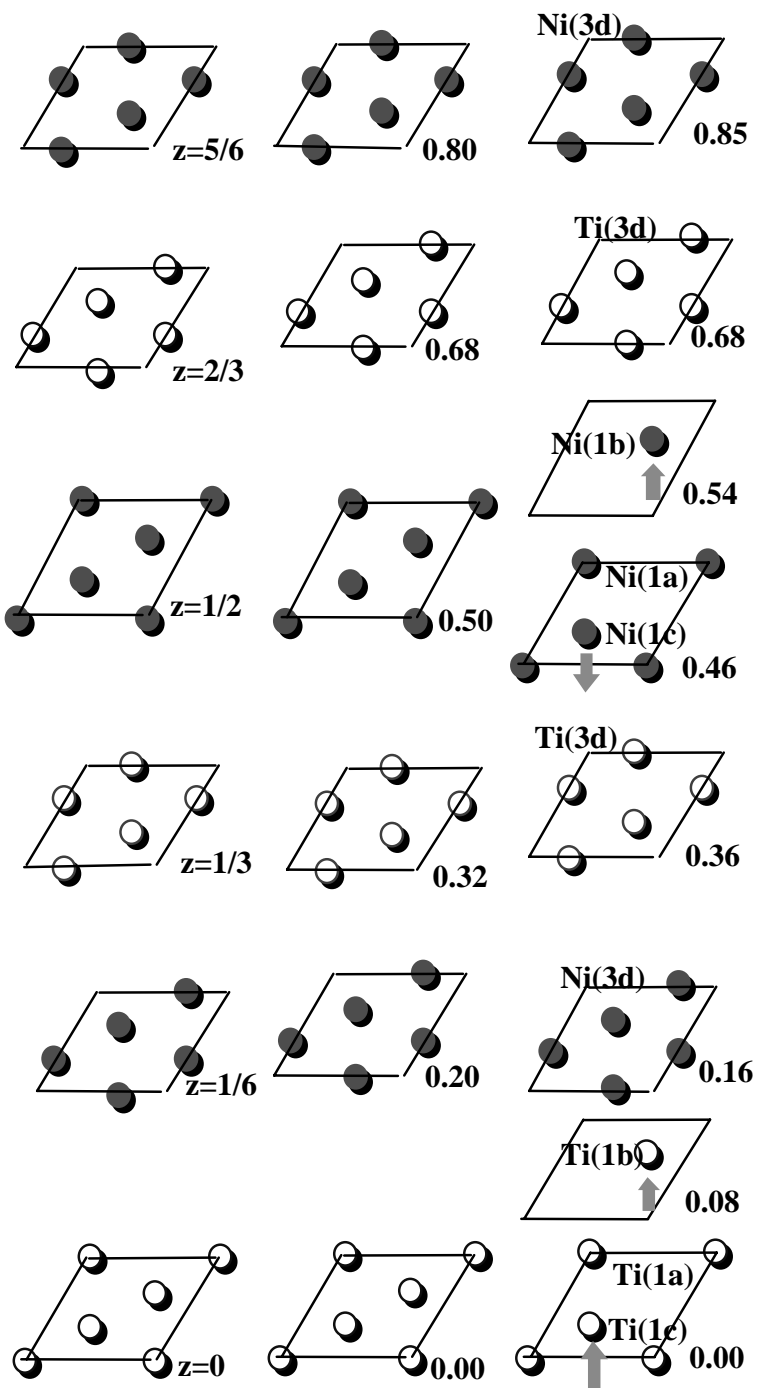

\section{$\mathrm{CsCl} \quad \mathrm{P} \overline{3} \operatorname{lm}($ Tri1 $) \quad \mathrm{P} 3(2$ Tri2)}

Fig. 1 Three types of crystal structures of TiNi. The (111) planes are arranged along the $\langle 111\rangle$ axis for the $\mathrm{CsCl}$ structure. The cirle and solid circle denote $\mathrm{Ti}$ and $\mathrm{Ni}$ atoms, respectively.

with the symmetry of the 143th group. If we chose the ratio of the atomic sphere radii so as to produce reasonable equilibrium lattice parameters, we could obtain satisfactory agreement between experimental and theoretical results for several types of compounds. In this paper, we also determined the ratio of the radii in the same way. We prepared several sets of the ratio of the radii and finally chose the following values; $R_{\mathrm{Ti}}: R_{\mathrm{Ni}}: R_{\mathrm{Fe}}=1.135: 1.0: 1.0$. The obtained lattice constants are $a=0.739810,0.732405$ and $0.727369 \mathrm{~nm}$ for $\mathrm{CsCl}$, Tri1 and Tri2 structures which are in good agreement with the experimental values of $0.73852,0.73800$ and $0.73580 \mathrm{~nm}$.

\section{Results and Discussion}

\subsection{Total energy and site preference of iron}

To determine the theoretical values, the total energies per formula unit $\left(\mathrm{TiNi}, \mathrm{TiNi}_{8 / 9} \mathrm{Fe}_{1 / 9}\right)$ were calculated as a func-
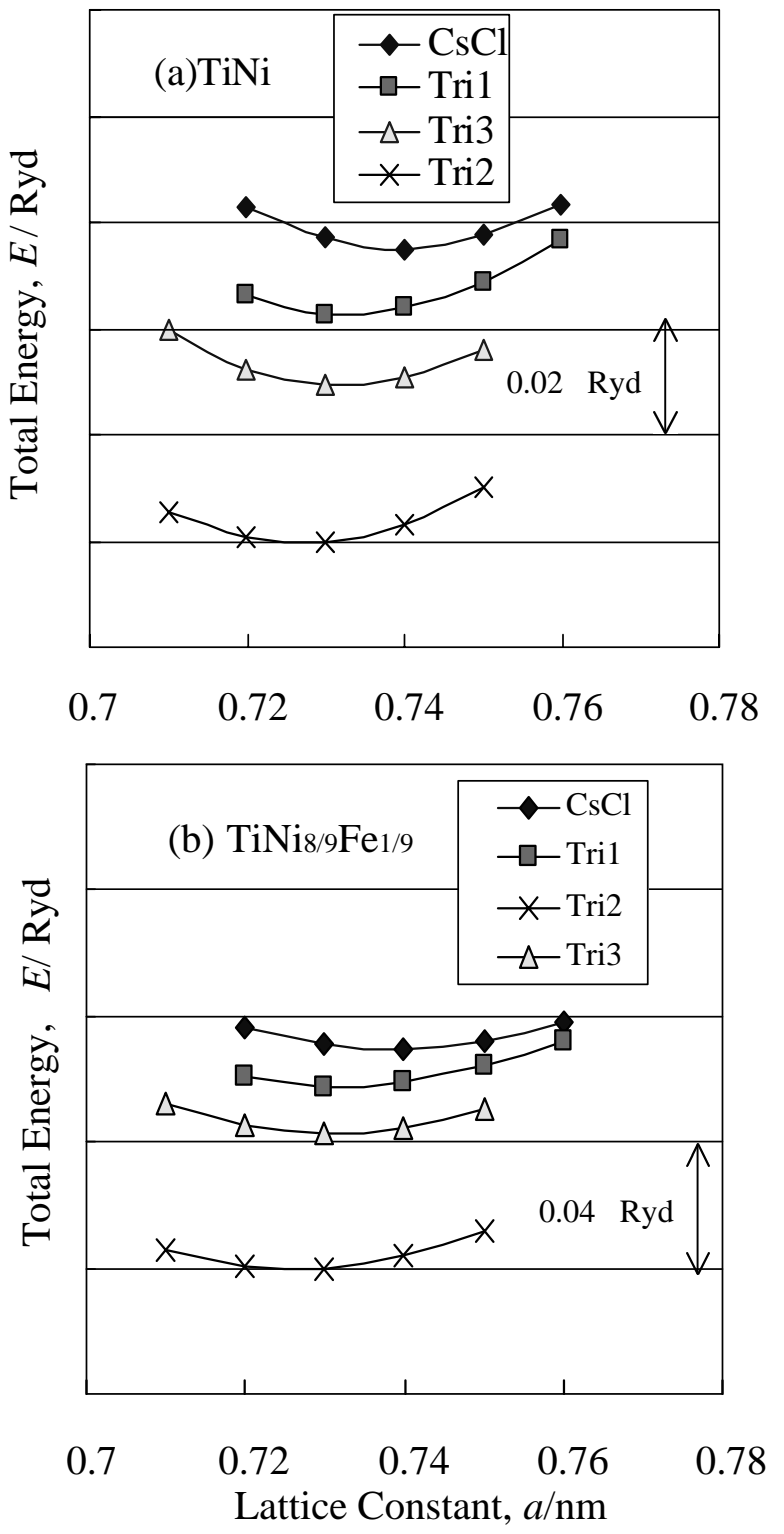

Fig. 2 Lattice constant dependence of total energies of TiNi (a) and $\mathrm{TiNi}_{8 / 9} \mathrm{Fe}_{1 / 9}$ (b) for the $\mathrm{CsCl}$, Tri1, Tri2 and Tri3 structures. The absolute values are arbitrary but the relative values are meaningful.

tion of the lattice constant, fixing the value of the ratio of $c / a$ which is equal to the experimental value. ${ }^{3,4)}$ Their curves for TiNi are shown in Fig. 2(a) for four structures. The minimum value becomes lower in the order of $\mathrm{CsCl}$, Tri1, Tri3 and Tri2. The parent phase $(\mathrm{CsCl})$ is most unstable and the Tri2 structure is most stable. We also notice that the difference of the total energies is large between Tri2 and Tri3 structures. This means that the approach between the $\mathrm{Ti}(1 \mathrm{c})$ and $\mathrm{Ni}(1 \mathrm{c})$ atoms largely contributes the stability of the P3 structure.

The total energies of $\mathrm{TiNi}_{8 / 9} \mathrm{Fe}_{1 / 9}$ are also shown in Fig. 2(b). The features are similar to ones of TiNi. It is seen that the energy of the P3 structure is lowest and that the energy difference between Tri2 and Tri3 structure is lager for $\mathrm{TiNi}_{8 / 9} \mathrm{Fe}_{1 / 9}$ than for TiNi. Thus, the added $\mathrm{Fe}$ atoms more stabilize the P3 structure.

In the $\mathrm{TiNi}_{8 / 9} \mathrm{Fe}_{1 / 9}$ which is an example of the alloy containing a small amount of $\mathrm{Fe}$ atoms, Fe atoms can occupy the $1 \mathrm{a}, 1 \mathrm{~b}$ and $1 \mathrm{c}$ sites. We did not treat the case where Fe atoms 
occupy the $3 \mathrm{~d}$ sites, because we have to consider $\mathrm{TiNi}_{6 / 9} \mathrm{Fe}_{3 / 9}$ where the concentration of $\mathrm{Fe}$ atoms is not small. Comparing the total energies of $\mathrm{TiNi}_{8 / 9} \mathrm{Fe}_{1 / 9}$ for the three cases, it was found that in the Tri2(P3) structure, the total energy is lowest for the case that Fe atoms occupy the 1c site. This suggests that the preferential site of $\mathrm{Fe}$ atoms is the 1c site and that when the parent phase transforms to the P3 phase, the transformation may occur so that $\mathrm{Fe}$ atoms shift to the 1c sites. That is, we guess that Fe atoms play a role as nuclei to form the P3 structure. Because the possibility that Fe atoms occupy other sites except for the 1c site increases with increasing concentration of Fe atoms, the martensitic transformation may be possible when the concentration of $\mathrm{Fe}$ atoms is very small, although it may be difficult when the concentration is large. Really, the P3 structure has been observed only for a small amount of $\mathrm{Fe}$ atoms.

\subsection{Band energy}

To examine the stabilization of the crystal structure in more detail, the band energies (Eband) were calculated, which were obtained by integrating the one-electron energies weighted by the density of states (DOS) over the states occupied by electrons. The differences ( $\triangle$ Eband) between the Eband for the $\mathrm{CsCl}$ structure and those for the other structures are estimated from the total and the local DOS of the constituent atoms. The values of $\Delta E$ band are for the unit cell where there is nine $\mathrm{Ti}$ atoms and nine $\mathrm{Ni}$ atoms. They are shown in Fig. 3(a) for TiNi. In the previous paper, the features about the Tri1 and Tri2 structures have already been described. Comparing the values of $\triangle E$ Eband of the Tri2 and Tri3 structures, it is seen that although the values are nearly equal for the $\mathrm{Ti}$ and $\mathrm{Ni}$ atoms at the $1 \mathrm{a}$ and $1 \mathrm{~b}$ sites, the values of the Ti(1c) and $\mathrm{Ni}(1 \mathrm{c})$ become more negative and ones of the $\mathrm{Ti}(3 \mathrm{~d})$ and
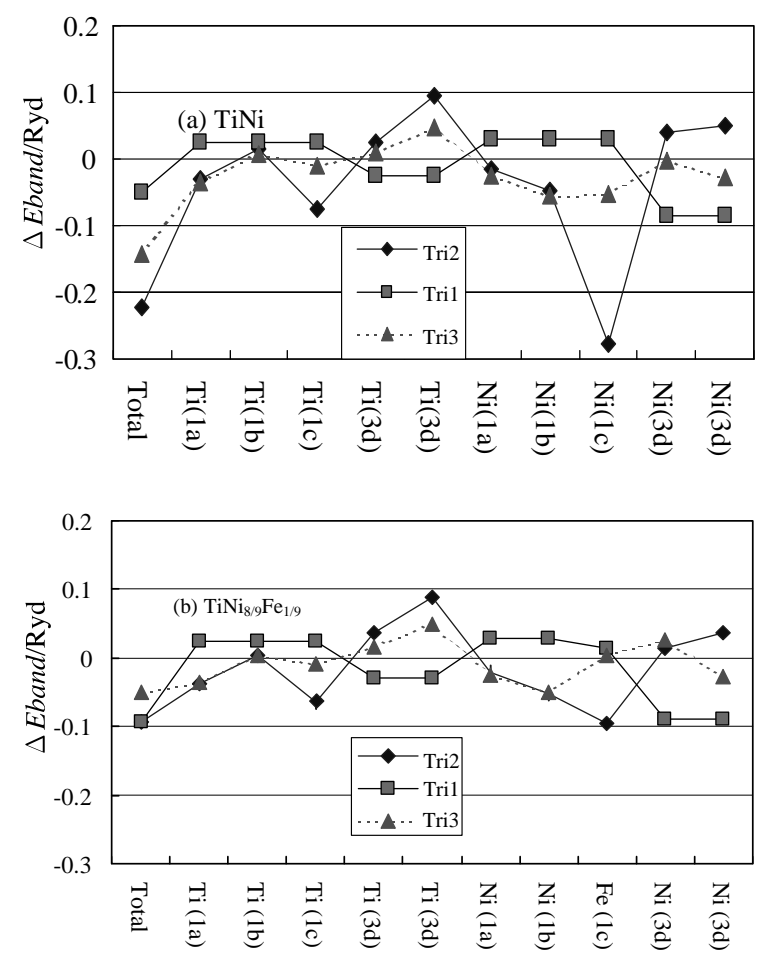

Fig. 3 Band energies of total valence electrons and constituent atoms of TiNi (a) and $\mathrm{TiNi}_{8 / 9} \mathrm{Fe}_{1 / 9}$ (b) for the Tri1, Tri2 and Tri3 structures.
$\mathrm{Ni}(3 \mathrm{~d})$ atoms more positive when the structure changes from the Tri3 to the Tri2 structure. Consequently, the approach between the $\mathrm{Ti}(1 \mathrm{c})$ and $\mathrm{Ni}(1 \mathrm{c})$ atoms contributes the stabilization of the Tri2 structure. Especially, the contribution of the $\mathrm{Ni}(1 \mathrm{c})$ atom is large.

The differences $\Delta$ Eband of $\mathrm{TiNi}_{8 / 9} \mathrm{Fe}_{1 / 9}$ are shown in Fig. 3(b). The features are similar to ones of TiNi except for the $\mathrm{Ni}(1 \mathrm{c})$ and $\mathrm{Fe}(1 \mathrm{c})$ atoms. Although the approach between the $\mathrm{Ti}(1 \mathrm{c})$ and $\mathrm{Fe}(1 \mathrm{c})$ atoms brings the energy gain to the band energy of the $\mathrm{Fe}(1 \mathrm{c})$ atom, it is small, compared with one of the Ni(1c) atom in TiNi. This is clearly seen in the local density of states (DOS) as seen later. The difference of the total energy between the Tri2 and the Tri3 structure is larger for $\mathrm{TiNi}_{8 / 9} \mathrm{Fe}_{1 / 9}$ than TiNi. Therefore, the other energies except for the band energy contribute the more stabilization of the Tri2 structure due to the replacement of the $\mathrm{Ni}$ atoms with $\mathrm{Fe}$ atoms.

\subsection{Density of states}

In the previous section, it was shown that the difference of the band energy of the constituent atoms helps us to know the contribution of each atom to the structural stability. In this section, the relation between the band energy and the density of states (DOS) is examined. We pay attention to the local DOS of Ni(1c) in TiNi which are compared for the $\mathrm{CsCl}$, Tri2 and Tri3 structures in Figs. 4(a) and (b). As described above, the sites of $\mathrm{Ti}(1 \mathrm{c})$ and $\mathrm{Ni}(1 \mathrm{c})$ atoms in the Tri3 structure are different from those in the Tri2 structure but the others are same in both the Tri2 and Tri3 structures. The Ti(1c) and $\mathrm{Ni}(1 \mathrm{c})$ atoms remain on the $\mathrm{Ti}(1 \mathrm{a})$ and $\mathrm{Ni}(1 \mathrm{a})$ planes, respectively, after the structure changes from the $\mathrm{CsCl}$ to the Tri3 structure. Then, the local DOS of Ni(1c) changes slightly as seen in Fig. 4(a) where the vertical lines indicate their Fermi levels. On the other hand, when the structure changes from
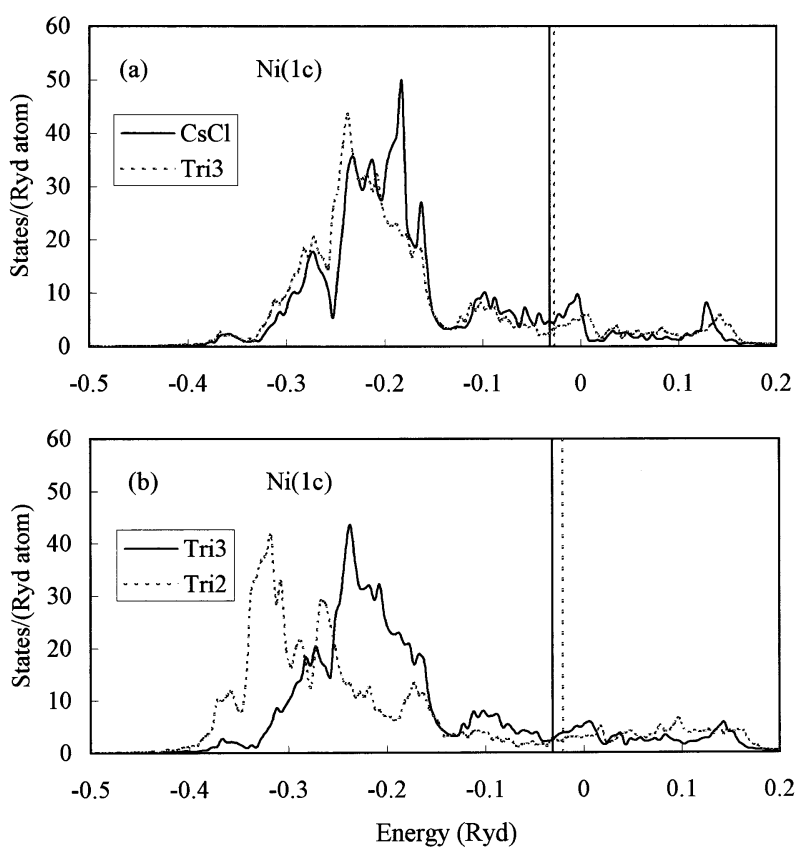

Fig. 4 Local DOS of the $\mathrm{Ni}(1 \mathrm{c})$ in TiNi. The curves of the $\mathrm{CsCl}$ and the Tri3 structures are compared in Fig. 4(a) and those of the Tri2 and Tri3 structures in Fig. 4(b). The vertical lines show the Fermi levels. 
the Tri3 to the Tri2 structure, the Ti(1c) and $\mathrm{Ni}(1 \mathrm{c})$ atoms shift from the $\mathrm{Ti}(1 \mathrm{a})$ and $\mathrm{Ni}(1 \mathrm{a})$ planes and approach each other. The first neighbor distance between the $\mathrm{Ti}(1 \mathrm{c})$ and $\mathrm{Ni}(1 \mathrm{c})$ is $22.7 \%$ shorter in the Tri2 structure, compared with that of the $\mathrm{CsCl}$ structure. The approach emphasizes the hybridization between the valence electrons of the $\mathrm{Ti}(1 \mathrm{c})$ and $\mathrm{Ni}(1 \mathrm{c})$ atoms and the local DOS of $\mathrm{Ni}(1 \mathrm{c})$ atoms moves to the lower energy range as seen in Fig. 4(b). This change of the local DOS brings the large energy gain to the Tri2 structure.

We turn our attention to the DOS of $\mathrm{TiNi}_{8 / 9} \mathrm{Fe}_{1 / 9}$ where the $\mathrm{Fe}$ atom can occupy the $1 \mathrm{a}, 1 \mathrm{~b}$ or $1 \mathrm{c}$ site. These Fe atoms are distinguished by the symbols of $\mathrm{Fe}(1 \mathrm{a}), \mathrm{Fe}(1 \mathrm{~b})$ and $\mathrm{Fe}(1 \mathrm{c})$. Their local DOS are shown in Fig. 5 for the three cases. As described in the Section 3.1, the total energy is highest for the case of $\mathrm{Fe}(1 \mathrm{a})$ and lowest for the case of $\mathrm{Fe}(1 \mathrm{c})$. Comparing the DOS of the three cases, it is found that the occupied states move to the lower energy states in the order of cases $\mathrm{Fe}(1 \mathrm{a}), \mathrm{Fe}(1 \mathrm{~b})$ and $\mathrm{Fe}(1 \mathrm{c})$. This suggests that when the structure transforms from the $\mathrm{CsCl}$ to the Tri3 (P3) structure, Fe atoms shift to the 1c sites as described in Section 3.1.

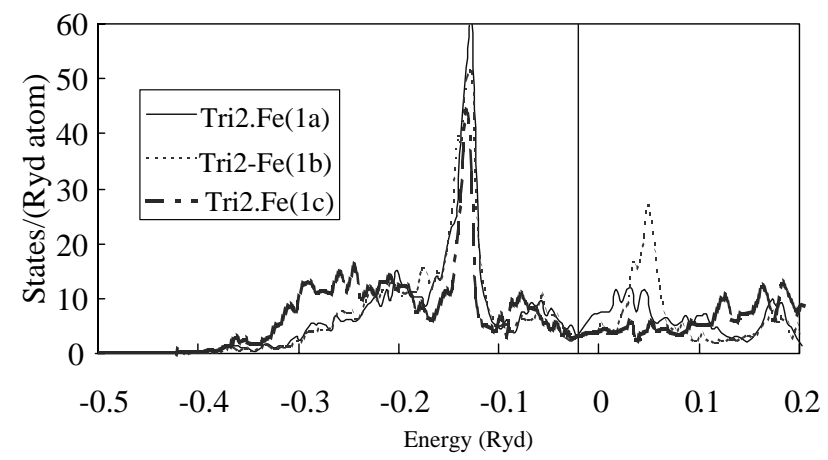

Fig. 5 Local DOS of the Fe atom at the 1a site (a), the $1 \mathrm{~b}$ site (b) or the 1c site (c) in $\mathrm{TiNi}_{8 / 9} \mathrm{Fe}_{1 / 9}$. The vertical line show the Fermi level.
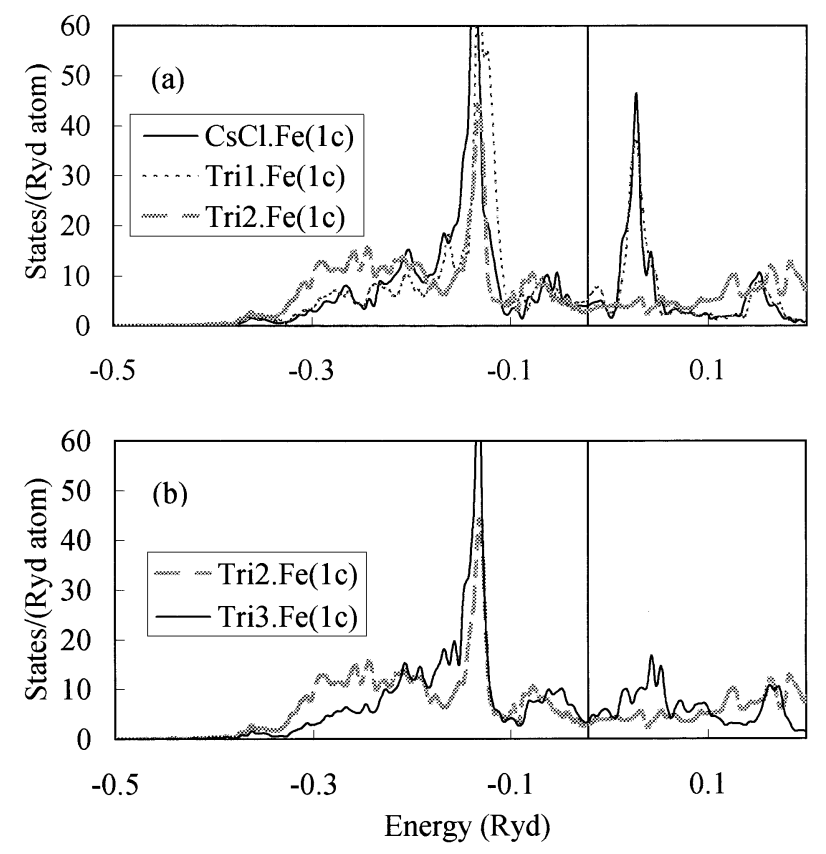

Fig. 6 Local DOS of the $\mathrm{Ni}(1 \mathrm{c})$ in $\mathrm{TiNi}_{8 / 9} \mathrm{Fe}_{1 / 9}$ for the $\mathrm{CsCl}$, Tril and Tri2 structures (a) and for the Tri2 and Tri3 (b). The vertical line show the Fermi level.
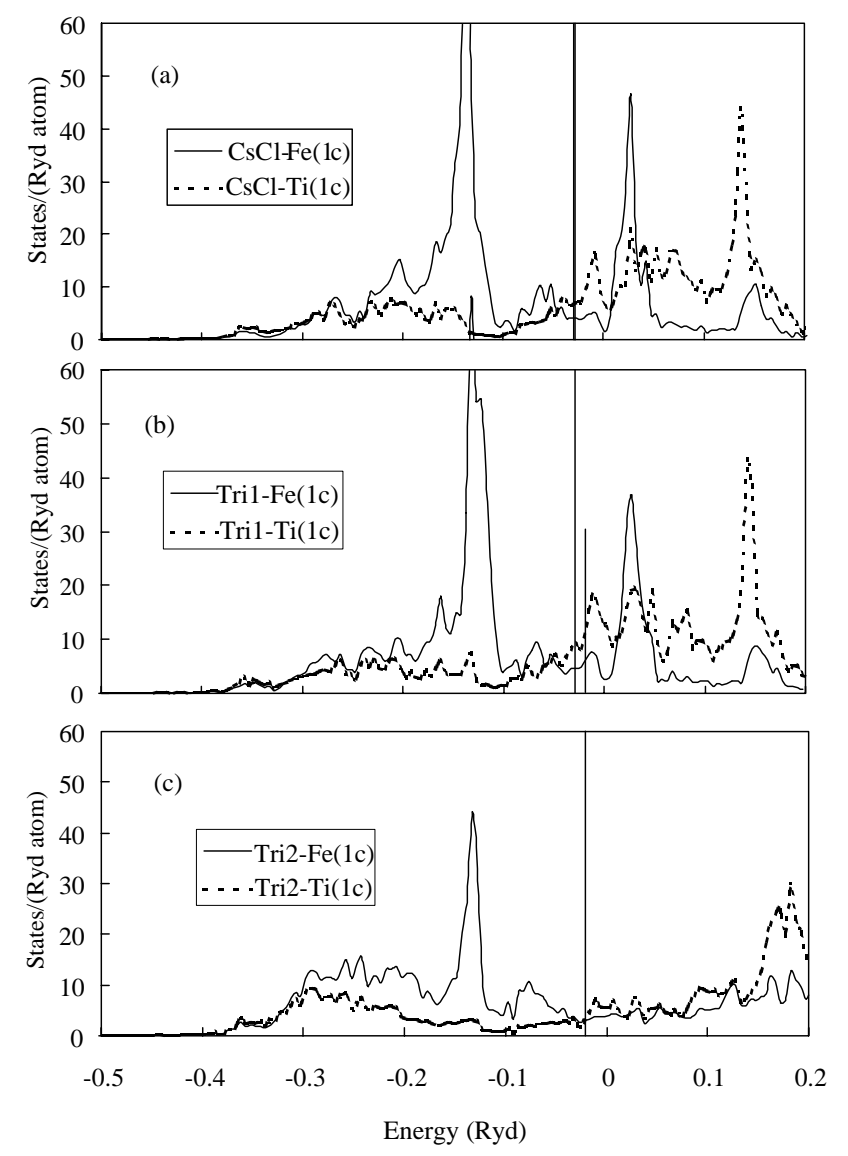

Fig. 7 Local DOS of the $\mathrm{Fe}(1 \mathrm{c})$ and $\mathrm{Ti}(1 \mathrm{c})$ in $\mathrm{TiNi}_{8 / 9} \mathrm{Fe}_{1 / 9}$ the $\mathrm{CsCl}(\mathrm{a})$, Tri1 (b) and Tri2 (c) structures. Solid and dotted curves denote Ni(1c) and Ti(1c), respectively. The vertical lines show the Fermi levels.

Next, the difference of the local DOS of $\mathrm{Fe}(1 \mathrm{c})$ atoms are compared for the four structures. Their curves are shown in Fig. 6(a) for the $\mathrm{CsCl}$, Tri1 and Tri2 structures and Fig. 6(b) for the Tri2 and Tri3 structures. Comparing the curves of the $\mathrm{CsCl}$ and Tril structures, it is found that the highest peak of the Tri1 shifts to the higher energy range, compared with one of the $\mathrm{CsCl}$ structure. In the Tri2 structure, the highest peak lowers and the occupied states move to the states with the lower energy. The occupied states increase around the energy range from -0.3 to $-0.2 \mathrm{Ryd}$. To focus the effect of the approach between the $\mathrm{Ti}(1 \mathrm{c})$ and $\mathrm{Fe}(1 \mathrm{c})$ atoms, the DOS curves of the Tri2 and Tri3 structures are compared in Fig. 6(b). The curve of the Tri3 structure is similar to one of the Tri1 structure. The difference of the occupancy of electrons are clearly seen between the Tri2 and Tri3 structures, as seen for the Ni(1c) in TiNi. That is, the approach between the Ti(1c) and $\mathrm{Fe}(1 \mathrm{c})$ lowers the band energy of the $\mathrm{Fe}(1 \mathrm{c})$ atom. Thus the DOS curves of the four structures shows that the band energy of the $\mathrm{Fe}(1 \mathrm{c})$ atom lowers in the order of the Tri1, the $\mathrm{CsCl}$, the Tri3 and the Tri2 structure, as seen in Fig. 3(b). Comparing the band energy of the Ni(1c) in Fig. 3(a) and one of the $\mathrm{Fe}(1 \mathrm{c})$ in Fig. 3(b), we notice that the energy gain of the $\mathrm{Fe}(1 \mathrm{c})$ atom is smaller, compared with one of the $\mathrm{Ni}(1 \mathrm{c})$ atom. This features are seen in the change of DOS shapes due to the change of the crystal structure, which is lager for the $\mathrm{Ni}(1 \mathrm{c})$ in TiNi than one of the $\mathrm{Fe}(1 \mathrm{c})$ in $\mathrm{TiNi}_{8 / 9} \mathrm{Fe}_{1 / 9}$.

The local DOS of $\mathrm{Ti}(1 \mathrm{c})$ and $\mathrm{Fe}(1 \mathrm{c})$ are shown in Fig. 7 
to see the difference of the hybridization between the valence electrons in the $\mathrm{CsCl}$, Tri1 and Tri2 structures. We notice that the $\mathrm{Ti}(1 \mathrm{c})$ and $\mathrm{Fe}(1 \mathrm{c})$ have peaks of their local DOS at same energy values. This suggests that the orbits of the $\mathrm{Ti}(1 \mathrm{c})$ and $\mathrm{Fe}(1 \mathrm{c})$ hybridize well. The curves of $\mathrm{Ti}(1 \mathrm{c})$ and $\mathrm{Fe}(1 \mathrm{c})$ are similar each other for the $\mathrm{CsCl}$ and Tril structures. In the Tri2 structure, the occupied states move to the lower energy range and the unoccupied states to the higher energy range, compared with those of the $\mathrm{CsCl}$ and Tril structures. This indicates that the hybridization between the orbits of $\mathrm{Ti}(1 \mathrm{c})$ and $\mathrm{Fe}(1 \mathrm{c})$ is stronger in the Tri2 structure because the the $\mathrm{Ti}(1 \mathrm{c})$ and $\mathrm{Fe}(1 \mathrm{c})$ atoms approaches each other. In the Tri2 structure, the local DOS in the lower energy range is higher for the $\mathrm{Ni}(1 \mathrm{c})$ in $\mathrm{TiNi}$ than for the $\mathrm{Fe}(1 \mathrm{c})$ in the $\mathrm{TiNi}_{8 / 9} \mathrm{Fe}_{1 / 9}$, as seen in Fig. 4 and Fig. 5 or Fig. 7(c). This may be because the potential around the $\mathrm{Ni}(1 \mathrm{c})$ is deeper than one of the $\mathrm{Fe}(1 \mathrm{c})$, therefore, the more electrons of $\mathrm{Ni}(1 \mathrm{c})$ hybridize with the electrons of $\mathrm{Ti}(1 \mathrm{c})$ in the lower energy range, compared with those of the $\mathrm{Fe}(1 \mathrm{c})$, when the $\mathrm{Ti}(1 \mathrm{c})$ and $\mathrm{Ni}(1 \mathrm{c})$ (or Fe(1c)) approach. Thus, as described in Sections 3 and 4, the energy gain due to the band energy of the $\mathrm{Ni}(1 \mathrm{c})$ atom is larger than one of the $\mathrm{Fe}(1 \mathrm{c})$ atom.

\section{Summary}

The electronic structures of the stoichiometric TiNi and the pseudo binary $\mathrm{TiNi}_{8 / 9} \mathrm{Fe}_{1 / 9}$ were calculated for the B2 structure and the three trigonal $(\mathrm{P} 3, \mathrm{P} \overline{3} \mathrm{~lm}$ and $\mathrm{P} 31 \mathrm{~m})$ structures. The total energy of the P3 structure is the lowest and that of the B2 structure is the highest. This suggests that the R-phase at low temperatures could be the P3 structure and the structure at high temperatures the B2 structure. The difference of the total energies between the P31m and the P3 structure is lager for $\mathrm{TiNi}_{8 / 9} \mathrm{Fe}_{1 / 9}$ than TiNi although the band energy is counter. This suggests that the P3 structure is more stabilized by the replacement of a small amount of $\mathrm{Ni}$ atoms with $\mathrm{Fe}$ atoms. It was also found that a small amount of iron prefer the 1c sites in the P3 structure. From the site preference of
Fe atoms in the P3 structure, we guessed that Fe atoms would play a role as nuclei to form the P3 structure.

We can also guess from the band energies of the constituent atoms that the approach between $\mathrm{Ti}(1 \mathrm{c})$ and $\mathrm{Ni}(1 \mathrm{c})$ (or $\mathrm{Fe}(1 \mathrm{c})$ ) atoms for the P3 structure brings the energy gain in the P3 structure. The hybridization between valence electrons of $\mathrm{Ti}(1 \mathrm{c})$ and $\mathrm{Ni}(1 \mathrm{c})$ (or $\mathrm{Fe}(1 \mathrm{c})$ ) atoms become stronger because of the approach. The features are clearly seen in the electronic structures. Thus, the band energy is a useful physical quantity to investigate the role of the constituent atoms in the stability of crystal structures.

\section{Acknowledgements}

The authors wish to thank Professor Takuya Ohba of Shimane University for giving information and significant discussions. This work was supported by a Grant-in-Aid for Scientific Research from the Ministry of Education, Culture, Sports, Science and Technology (13640368).

\section{REFERENCES}

1) Y. Kudoh, M. Tokonami, S. Miyazaki and K. Otsuka: Acta Metall. 33 (1985) 2049-2056.

2) S. Vatanayon and R. F. Hehemann: 'Martensitic Transformations in $\beta$ phase Alloys', Shape Memory Effects in Alloys, J. Perkins ed. (Plenum Press, New York, 1975) pp. 115-145.

3) E. Goo and R. Sinclair: Acta Metall. 33 (1985) 1717-1722.

4) T. Ohba, Y. Emura and K. Otsuka: Mater. Trans., JIM 33 (1992) 23-37.

5) T. Hara, T. Ohba, E. Okumishi and K. Otsuka: Mater. Trans., JIM 38 (1997) 11-17.

6) S. Ishida, T. Tasaka and S. Asano: Proc. of Pacific Rim International Conference on Advanced Materials and Processing (PRICM-4): ed. by S. Hanada, Z. Zhong, S. W. Nam and R. N. Wright (The Japan Inst. Metals, 2001) pp. $1835-1838$.

7) O. K. Andersen, O. Jepsen and D. Glotzel: Proc. Int. School of Physics "Enrico Fermi" Course 89, ed. F. Bassami, F. Fumi and M. P. Tosi (North-Holland, Amsterdam, 1985) pp. 59-176.

8) V. L. Moruzzi, J. F. Janak and A. R. Williams: Calculated Electronic Properties of Metals (pergamon, New York, 1978) pp. 1-22. 